OLIVEIRA, E.Q.; BEZERRA NETO, F.; NEGREIROS, M.Z.; BARROS JÚNIOR, A.P. Desempenho agroeconômico do bicultivo de alface em sistema solteiro e consorciado com cenoura. Horticultura Brasileira, Brasília, v.22, n.4, p.712-717, out-dez 2004.

\title{
Desempenho agroeconômico do bicultivo de alface em sistema solteiro e consorciado com cenoura
}

\author{
Eliane Q. de Oliveira; Francisco Bezerra Neto; Maria Zuleide de Negreiros; Aurélio P. Barros Júnior \\ ESAM, NPG, C. Postal. 137, 59625-900 Mossoró-RN; E-mail: bezerra@esam.br
}

\section{RESUMO}

Dois experimentos foram implantados de setembro a dezembro/ 2002, na ESAM (RN), para avaliar o desempenho agroeconômico do bicultivo de dois grupos de alface em sistema solteiro e consorciado com duas cultivares de cenoura em faixas. O delineamento experimental foi de blocos balanceados em grupos, com quatro repetições. Foram avaliadas as cultivares pertencentes aos grupos crespa (Lucy Brown, Tainá, Laurel e Verônica) e lisa (Babá de Verão, Maravilha das Quatro Estações, Elisa e Carolina). No experimento consorciado foi utilizado o esquema de parcelas sub-divididas, onde os tratamentos designados às parcelas foram as cvs. de cenoura Alvorada e Brasília e os designados às sub-parcelas foram as cvs. de alface do grupo crespa e as do grupo lisa. Na alface foi avaliado o rendimento de folhas e na cenoura o rendimento total, comercial e a classe das raízes. Foram usados índices agroeconômicos para medir a eficiência do sistema consorciado: Índice de Uso Eficiente da Terra, Renda Bruta, Renda Líquida, Vantagem Monetária, Vantagem Monetária Corrigida, Taxa de Retorno e Índice de Lucratividade. Não houve interação significativa entre os fatores cvs. de cenoura e cvs. de alface sobre os rendimentos das culturas. As cvs. de cenoura não influenciaram os rendimentos das culturas. As cvs. de alface não afetaram os rendimentos da cenoura. No bicultivo da alface consorciada com cenoura, recomenda-se o emprego das cvs Lucy Brown e Tainá do grupo crespa ou da 'Babá de Verão' e 'Maravilha das Quatro Estações' do grupo lisa no primeiro plantio. No segundo plantio, apenas a cv. do grupo lisa Maravilha das Quatro Estações se sobressaiu das demais no desempenho produtivo em cultivo consorciado.As cultivares de alface do grupo crespa consorciadas com cenoura se sobressaíram daquelas do grupo lisa no desempenho produtivo. Os consórcios cenoura 'Alvorada' $\mathrm{x}$ alface 'Lucy Brown'; e cenoura 'Brasília' x alface 'Maravilha das Quatro Estações', tiveram os melhores indicadores agroeconômicos, com índices de uso eficiente da terra de 2,16 e 2,15, taxas de retorno de 2,05 e 2,33 , e índices de lucratividade de $53,92 \%$ e $59,83 \%$, respectivamente.

Palavras-chave: Daucus carota, Lactuca sativa, eficiência agroeconômica.

\begin{abstract}
Agrieconomic performance of lettuce under bicropping, sole crop and intercropped with carrot
\end{abstract}

Two experiments were carried out from September to May 2002, in Mossoró, Rio Grande do Norte State, Brazil, to evaluate the agrieconomic performance of two lettuce groups under bicropping, sole crop and intercropping system with two carrot cultivars (Alvorada and Brasília) in a strip-intercropping arrangement. The experimental design was of group balanced blocks with four replications. The evaluated lettuce cvs. were from the crispleaf group (Lucy Brown, Tainá, Laurel and Verônica) and looseleaf group (Babá de Verão, Maravilha das Quatro Estações, Elisa and Carolina). In the intercropping experiment, the split-plot scheme was used. In the plots the carrot cvs. were assigned and in the subplots the lettuce cvs. of both groups. From the lettuce cvs. were obtained data of leaf yield and, for the carrot cvs. were obtained total and commercial yield, besides the root classes. Agrieconomic indices such as land equivalent ratio, gross and net income, monetary advantage, rate of return and profit margin were used to measure the efficiency of intercropping systems. No significant interaction was obtained between carrot and lettuce cvs. in yield of both crops. Carrot cvs. did not influence crop yield and lettuce cvs. had no influence on carrot yield. In the bicropping of lettuce with carrot, the cvs. Lucy Brown and Tainá (crispleaf group) and Babá de Verão and Maravilha das Quatro Estações (looseleaf group) had presented the best yield performance in the first planting. In the second planting, only cv. Maravilha das Quatro Estações of looseleaf lettuce group had presented the best performance under intercropping. Lettuce cvs. of crispleaf group intercropped with carrot had presented the best yield performance when compared to those of the looseleaf group. The intercropping systems of carrot 'Alvorada' $x$ lettuce 'Lucy Brown' and carrot 'Brasília' x lettuce 'Maravilha das Quatro Estações' in a strip arrangement of four carrot rows alternated with four lettuce rows resulted in the best agrieconomic indicators, with land equivalent ratios of 2.16 and 2.15 , rates of return of 2.05 and 2.33, and profit margins of $53.92 \%$ and $59.83 \%$, respectively.

Keywords: Daucus carota, Lactuca sativa, agrieconomic efficiency.

(Recebido para publicação em 20 de janeiro de 2004 e aceito em 13 de setembro de 2004)

$\mathrm{U}$ ma das práticas agrícolas que vem sendo usada com sucesso na olericultura é a consorciação de culturas, principalmente quando realizada em moldes agroecológicos, apresentando ganhos na produtividade, no valor nutricional, econômico e ambiental. Com esta prática busca-se uma maior produção por área, pela disposição de plantas que irão melhor utilizar o espaço, nutrientes, área e luz solar, além dos benefícios que uma planta traz a outra no controle de plantas daninhas, pragas e doenças (Souza e Resende, 2003). Entre as oleráceas que se pode combinar com vantagens agroeconômicas e ambientais, estão a alface e cenoura (Andrade et al., 2001; Oliveira et al.,
2002; Bezerra Neto et al., 2003). São bastante usadas na alimentação humana e contribuem primariamente com vitaminas e sais minerais, sendo a cenoura, uma das melhores fontes vegetais de beta caroteno.

No consórcio, as culturas envolvidas não são, necessariamente, semeadas ao mesmo tempo, mas durante parte do 
seu desenvolvimento haverá uma simultaneidade, forçando a interação entre elas. Para tanto, é importante a escolha de culturas companheiras que exerçam alguma complementaridade. Isso é possível quando as espécies apresentam nichos ecológicos diferentes podendo assim maximizar a utilização da luz e a absorção de nutrientes mais do que uma única cultura numa área e tempo determinados. A diversificação de culturas é o ponto chave para a manutenção da fertilidade dos sistemas, para o controle de pragas e doenças e para a estabilidade econômica regional (Khatounian, 2001).

Apesar dos sistemas de produção de hortaliças estarem voltados para o cultivo solteiro, há estudos envolvendo agrossistemas consorciados (Garzim, 1987; Azevedo Júnior, 1990; Sudo et al., 1997; Caetano et al., 1999; Porto, 1999; Saldanha et al., 2001) devido a razões biológicas, nutricionais, econômicas e sociais, pois representam uma alternativa para produzir alimentos e renda sob situações de cultivo onde os recursos são limitados.

Com o aparecimento de novas cultivares tanto de alface como de cenoura, em fase de adaptação às condições do Nordeste brasileiro, torna-se importante a busca de informações e a obtenção de dados comparativos sobre o seu comportamento em agroecossistemas consorciados. Busca-se cultivares que proporcionem boa capacidade de combinação interespecífica e, conseqüentemente, maior produção e eficiência agroeconômica nesses sistemas. No consórcio cenoura $\mathrm{x}$ alface, a redução no rendimento da cenoura pode ser pequena, se manejos adequados forem feitos nos espaçamentos, arranjo de plantio e cultivares, entre outros fatores que afetam o uso de recursos e a produtividade das culturas componentes.

A fim de obter subsídios para o desenvolvimento de sistemas consorciados sustentáveis de cenoura e alface, o presente trabalho visa avaliar o desempenho agroeconômico do bicultivo de dois grupos de alface (crespa e lisa), em sistemas solteiro e consorciado em faixa com duas cultivares de cenoura.

\section{MATERIAL E MÉTODOS}

Dois experimentos foram realizados na horta da ESAM, em Mossoró, de se- tembro a dezembro/2002, em Argissolo Vermelho Amarelo Eutrófico. O clima da região, segundo a classificação Köppen, é BSwh', seco e muito quente, com duas estações climáticas: uma seca que vai geralmente de junho a janeiro, e uma chuvosa, de fevereiro a maio. Foram retiradas amostras da área experimental, cujas análises forneceram os seguintes resultados, para os experimentos solteiro e consorciado, respectivamente: $\mathrm{pH}$ (água 1:2,5) = 7,75 e 7,75; $\mathrm{Ca}=7,40$ e 7,12 $\mathrm{cmol}_{\mathrm{c}} \mathrm{dm}^{-3} ; \mathrm{Mg}=4,30$ e 4,22 $\mathrm{cmol}_{\mathrm{c} \mathrm{dm}} \mathrm{d}^{-3} ; \mathrm{K}=2,00$ e $1,42 \mathrm{cmol}_{\mathrm{c}}$ $\mathrm{dm}^{-3} ; \mathrm{Na}=0,50$ e $0,49 \mathrm{cmol} \mathrm{dm}^{-3} ; \mathrm{Al}=$ 0,00 e $0,00 \mathrm{cmol}_{\mathrm{c}} \mathrm{dm}^{-3}$ e $\mathrm{P}=827,50$ e 452,5 $\mathrm{mg} \mathrm{dm}^{-3}$.

O delineamento experimental usado tanto no experimento solteiro como no consorciado foi o de blocos balanceados em grupos, com quatro repetições. Avaliou-se os grupos de alface crespa (Lucy Brown, Tainá, Laurel e Verônica) e lisa (Babá de Verão, Maravilha das Quatro Estações, Elisa e Carolina). No experimento consorciado foi utilizado o esquema de parcelas sub-divididas, onde os tratamentos designados às parcelas foram as cultivares de cenoura (Alvorada e Brasília) e os designados às sub-parcelas foram os grupos de alface. As parcelas no cultivo solteiro tinham área total de 1,20 m², com área útil para alface de $0,48 \mathrm{~m}^{2}$, contendo 12 plantas no espaçamento de $0,20 \times 0,20$ m, e para cenoura área útil de $0,60 \mathrm{~m}^{2}$, contendo 30 plantas no espaçamento de $0,20 \times 0,10 \mathrm{~m}$.

As parcelas do cultivo consorciado, constituídas de quatro faixas alternadas (duas de cenouras e duas de alface com quatro fileiras cada), tinham área total de $3,84 \mathrm{~m}^{2}$, com área útil de $1,60 \mathrm{~m}^{2}$, contendo 80 plantas de cenoura e 40 plantas de alface, com espaçamento de $0,80 \mathrm{~m}$ entre faixas de quatro fileiras e de 0,20 x 0,05 m entre fileiras e plantas de cenoura e de $0,20 \times 0,10 \mathrm{~m}$ entre fileiras e plantas de alface.

A cv. de alface Lucy Brown, do tipo americana, apresenta boa compacidade de cabeça, coração pequeno de coloração verde clara, plantas grandes com folhas grossas, dando ótima proteção à cabeça e boa resistência ao pendoamento precoce; Tainá, do tipo americana é indicada para o consumo fresco devido ao seu excelente sabor; caracteriza-se por alta compacidade e tamanho de cabeças, boa formação de ombro e alta resistência ao pendoamento precoce; Laurel, do tipo americana, selecionada para cultivo em condições de meia estação e verão intenso, caracteriza-se por apresentar boa compacidade das cabeças, alta uniformidade de formato e tamanho, excelente formação de base e boa resposta fitossanitária sob alta pressão de septoriose e cercosporiose; a planta tem aptidão para comercialização em caixas ou em bandejas; Verônica, apresenta plantas de porte grande, folhas verde claras e alta resistência ao pendoamento precoce; Babá de Verão, de coloração verde clara tem porte mediano e não forma cabeça; apresenta baixa resistência ao pendoamento precoce; Maravilha das Quatro Estações, cultivar exótica de folhas avermelhadas e destina-se ao mercado diferenciado; não possui resistência ao vírus do mosaico da alface; Elisa, considerada padrão de mercado com plantas de porte grande, cabeças compactas e folhas verde claras, alta uniformidade de campo e alto rendimento no embalamento, alta resistência ao pendoamento e tolerância ao vírus do mosaico da alface, estirpe 2; As plantas de Carolina são volumosas, formam cabeça, têm folhas grandes e macias, de coloração verde clara, são resistentes ao pendoamento precoce com excelente padrão comercial e desempenho no verão (Sementes Sakama, 2002).

A cultivar de cenoura Alvorada apresenta coloração externa alaranjada intensa e pigmentação internamente distribuída entre o xilema e o floema, contendo teor de carotenóides totais cerca de $35 \%$ superior às demais cultivares e menor incidência de ombro verde; tem alta resistência à queima-das-folhas, viabilizando a produção praticamente sem o emprego de agrotóxicos, o que a torna indicada para cultivos orgânicos; é recomendada para o plantio de verão nas principais regiões produtoras; Brasília é indicada para o cultivo de verão, tem folhagem vigorosa e coloração verde escura, raízes de pigmentação alaranjada escura, baixa incidência de ombro verde ou roxo e boa resistência à queima-das-folhas; é recomenda- 
da para semeaduras de outubro a fevereiro, nas regiões Centro-Oeste, Norte e Nordeste do Brasil (Souza et al., 2002).

Foi feita a solarização da área durante 50 dias para desinfestação do solo em pré-plantio, como controle de fitopatógenos. Durante a condução do experimento foram efetuadas capinas manuais, irrigação pelo sistema de micro-aspersão e levantamento da parte aérea (ou da saia) com fitilho da primeira e quarta fileira da faixa de cenoura com o objetivo de diminuir o sombreamento da primeira ou quarta fileira da faixa de alface.

Nos canteiros de plantio foram realizadas a adubação com 80 t/ha de esterco de bovino e com $40 \mathrm{~kg} / \mathrm{ha}$ de nitrogênio (uréia), $60 \mathrm{~kg} / \mathrm{ha}$ de $\mathrm{P}_{2} \mathrm{O}_{5}$ (superfosfato simples) e $30 \mathrm{~kg} / \mathrm{ha}$ de $\mathrm{K}_{2} \mathrm{O}$ (cloreto de potássio), nas parcelas cultivadas com cenoura e alface solteira e em consórcio, de acordo com análise do solo.

Nas parcelas consorciadas da cenoura, foi realizada uma adubação nitrogenada em cobertura aos 37 dias após a semeadura com 45,45 kg/ha de uréia, enquanto que nas parcelas de alface efetuaram-se adubações foliares de $30 \mathrm{ml} / 20 \mathrm{~L}$ de água da formulação 14 4-6, $0,8 \%$ de $\mathrm{S}, 1,5 \%$ de $\mathrm{Mg}, 2 \%$ de $\mathrm{Zn}$, $1,5 \%$ de $\mathrm{Mn}, 0,1 \%$ de B e $0,05 \%$ de Mo, aos 28, 39 e 44 dias após semeadura.

Nos dois cultivos sucessivos, em 5 de setembro e 14 de novembro/2002, as cultivares de alface foram semeadas em copos descartáveis de $150 \mathrm{ml}$, contendo mistura de vermiculita e húmus como substrato, na proporção de 1:2. Foram semeadas, em cada cultivo, três a cinco sementes por recipiente, efetuando-se dois desbastes, sendo o primeiro aos oitos dias após emergência, deixando-se três plântulas/recipiente e o segundo aos quinze dias, deixando-se uma plântula/ recipiente. As mudas de alface foram produzidas sob sombreamento, utilizandose um abrigo coberto com tela de náilon de cor branca, e transplantadas aos 21 dias após a semeadura para as faixas adjacentes da cenoura, quando a cultura da cenoura se encontrava com 7 e 78 dias da semeadura, respectivamente no primeiro e no segundo cultivo.

A cenoura, cultura principal, foi semeada em 18/09/02. Foram realizados dois desbastes, aos 22 dias após se- meadura e aos 30 dias, deixando-se apenas uma planta a cada $0,05 \mathrm{~m}$. As colheitas da alface no primeiro cultivo foram realizadas nos dias 16 e 21/10/02, estando a cenoura aos 28 dias da semeadura e a alface entre 41 e 46 dias da semeadura. As colheitas da cenoura foram realizadas nos dias 17 e 18/12/02. As colheitas das cultivares de alface no segundo cultivo foram realizadas nos dias 23 e 24/12/02, cerca de uma semana após as colheitas da cenoura, estando a alface aos 39 e 40 dias da semeadura, respectivamente.

Para a alface avaliou-se o rendimento (peso da matéria fresca da parte aérea de todas as plantas da parcela útil em t/ha). Para a cenoura avaliaram-se os rendimentos total (peso das raízes das plantas da parcela útil em $\mathrm{t} / \mathrm{ha}$ ), comercial [peso das raízes das plantas da parcela útil, livres de defeitos (rachaduras, bifurcações, nematóides e danos mecânicos) em t/ha] e classe de raízes [de acordo com o comprimento e maior diâmetro transversal (longas, com comprimento de 17 a $25 \mathrm{~cm}$ e diâmetro menor que $5 \mathrm{~cm}$; médias, com comprimento de 12 a $17 \mathrm{~cm}$ e diâmetro maior que $2,5 \mathrm{~cm}$; curtas, com comprimento de 5 a $12 \mathrm{~cm}$ e diâmetro maior que $1 \mathrm{~cm}$ e refugo composto por raízes que não se enquadram nas medidas anteriores, conforme Vieira et al., 1997)]. As relações provenientes dos rendimentos total e comercial nos sistemas consorciados e rendimentos nos sistemas solteiros foram determinadas e expressas em percentagens.

Alguns índices agroeconômicos foram usados para avaliar a eficiência dos sistemas consorciados (Beltrão et al., 1984): índice de uso eficiente da terra (UET), renda bruta $(\mathrm{RB})$, renda líquida $(\mathrm{RL})$, vantagem monetária (VM), vantagem monetária corrigida (VMc), taxa de retorno (TR) e índice de lucratividade (IL).

$\mathrm{O}$ índice UET é dado pela expressão: $\left(\mathrm{I}_{\text {cenoura }} / \mathrm{S}_{\text {cenoura }}\right)+\left(\mathrm{I}_{\text {alface }} / \mathrm{S}_{\text {alface }}\right)$, onde I e $S$ representam os rendimentos dos sistemas consorciado e solteiro de cada cultura componente e é definido como a área relativa de terra, sob condições de plantio isolado, que é requerida para proporcionar os rendimentos alcançados no consórcio.

A renda bruta $(\mathrm{RB})$ foi obtida multiplicando-se os rendimentos da cultura em cada tratamento pelo valor do produto pago ao produtor no mês de dezembro de 2002 , de $\mathrm{R} \$ 1,10 / \mathrm{kg}$ para a alface crespa, $\mathrm{R} \$ 1,00 / \mathrm{kg}$ para a alface lisa e $\mathrm{R} \$ 0,65 / \mathrm{kg}$ para a cenoura.

A renda líquida (RL) foi calculada subtraindo-se da renda bruta, os custos de produção, provenientes de insumos e serviços. Estes custos (C) foram calculados para cada tratamento, baseado nos coeficientes de custo de insumos e serviços utilizados em um hectare de cenoura e alface em nível experimental. Foram considerados os preços de insumos e serviços vigentes no mês de outubro de 2002, na cidade de Mossoró.

A vantagem monetária e a vantagem monetária corrigida foram obtidas pelas expressões: $\mathrm{VM}=\mathrm{RB} \times(\mathrm{UET}-1)$ / UET e VMc $=$ RL x (UET-1)/UET. A taxa de retorno (TR) por real investido em cada tratamento foi obtida por meio da relação entre a renda bruta $(\mathrm{RB})$ e o custo de produção $(\mathrm{C})$ de cada tratamento. $\mathrm{O}$ índice de lucratividade (IL) foi obtido da relação entre a RL e RB e expresso em percentagem.

Análise univariada de variância para o delineamento de blocos balanceados em grupos foi utilizada para avaliar as características da alface e cenoura. $\mathrm{O}$ teste de Duncan foi usado para comparar as médias dos níveis dos tratamentos. O software utilizado na análise estatística foi o SPSS/PC (Norusis, 1990).

\section{RESULTADOS E DISCUSSÃO}

No experimento solteiro, primeiro plantio da alface, houve efeito significativo de grupos de cultivares e de cultivares dentro do grupo crespa no rendimento da alface (Tabela 1). O grupo crespa teve o maior rendimento e dentro deste grupo as cultivares de alface Lucy Brown e Tainá se destacaram das demais no desempenho produtivo. No segundo plantio não foi observada diferença significativa entre grupos e cultivares dentro do grupo (Tabela 1). Este resultado provavelmente se deve ao crescimento e desenvolvimento das cultivares no período mais quente do ciclo, nivelando os rendimentos das cultivares e do grupo de cultivares. A alface quando cultivada em períodos com temperatura e luminosidade elevadas 
Tabela 1. Rendimento de alface no cultivo solteiro e consorciado no primeiro e segundo plantio em função de cultivares de cenoura, grupos e cultivares de alface testadas. Mossoró-RN, ESAM, 2002.

\begin{tabular}{|c|c|c|c|c|}
\hline \multirow{3}{*}{ Cultivares de cenoura } & \multicolumn{4}{|c|}{ Rendimento (t/ha) } \\
\hline & \multicolumn{2}{|c|}{ Cultivo solteiro } & \multicolumn{2}{|c|}{ Cultivo consorciado } \\
\hline & $1^{\circ}$ plantio & $2^{\circ}$ plantio & $1^{\circ}$ plantio & $2^{\circ}$ plantio \\
\hline $\begin{array}{l}\text { Alvorada } \\
\text { Brasília }\end{array}$ & * & & $\begin{array}{l}6,67 \mathrm{a} \\
7,59 \mathrm{a}\end{array}$ & $\begin{array}{l}7,16 \text { a } \\
7,00 \text { a }\end{array}$ \\
\hline \multicolumn{5}{|l|}{ Grupo/cvs. de alface } \\
\hline CRESPA & $15,23 \mathrm{~A}$ & $17,11 \mathrm{~A}$ & $7,80 \mathrm{~A}$ & $7,58 \mathrm{~A}$ \\
\hline $\begin{array}{l}\text { Lucy Brown } \\
\text { Tainá } \\
\text { Laurel } \\
\text { Verônica }\end{array}$ & $\begin{array}{l}19,26 \text { a } \\
17,10 a \\
12,61 \quad b \\
11,43 \text { b }\end{array}$ & $\begin{array}{l}16,05 \text { a } \\
17,51 \text { a } \\
16,87 \text { a } \\
17,99 \text { a }\end{array}$ & $\begin{array}{c}10,17 \text { a } \\
9,12 \text { a } \\
5,48 \text { b } \\
6,41 \text { b }\end{array}$ & $\begin{array}{l}8,36 \text { a } \\
6,94 \text { a } \\
7,92 \text { a } \\
7,10 \text { a }\end{array}$ \\
\hline LISA & $13,13 \quad B$ & $19,39 \mathrm{~A}$ & $6,46 \quad B$ & $6,58 \mathrm{~B}$ \\
\hline $\begin{array}{l}\text { Babá de Verão } \\
\text { M. das Quatro Estações } \\
\text { Elisa } \\
\text { Carolina }\end{array}$ & $\begin{array}{l}14,78 \mathrm{a} \\
13,08 \mathrm{a} \\
12,41 \mathrm{a} \\
12,25 \mathrm{a}\end{array}$ & $\begin{array}{l}21,68 \text { a } \\
21,37 \text { a } \\
18,41 \text { a } \\
16,09 \text { a }\end{array}$ & $\begin{array}{l}8,16 \text { a } \\
7,35 \text { a } \\
5,23 \text { b } \\
5,08 \text { b }\end{array}$ & $\begin{array}{l}5,90 \mathrm{~b} \\
8,49 \mathrm{a} \\
5,54 \mathrm{~b} \\
6,37 \mathrm{ab}\end{array}$ \\
\hline $\begin{array}{l}\text { C.V. (a) (\%) } \\
\text { C.V. (b) }(\%) \\
\text { C.V. (c) }(\%)\end{array}$ & $\begin{array}{l}12,22 \\
24,37\end{array}$ & $\begin{array}{l}24,30 \\
20,12\end{array}$ & $\begin{array}{l}32,30 \\
23,44 \\
36,48\end{array}$ & $\begin{array}{l}51,27 \\
25,16 \\
24,76\end{array}$ \\
\hline
\end{tabular}

* Médias seguidas por letras minúsculas ou maiúsculas diferentes, nas colunas, diferem entre si pelo teste de Duncan, $(\mathrm{P}<0,05)$.

não consegue desenvolver seu máximo potencial genético, acarretando assim redução de seu ciclo cultural, diminuição ou estagnação da produção.

No experimento consorciado, primeiro plantio, não foi observado efeito de interação entre cultivares de cenoura e grupo de cultivares ou entre cultivares de cenoura e cultivares de alface dentro do grupo no rendimento da alface (Tabela 1). Os grupos de cultivares e as cultivares de alface dentro do grupo diferiram de maneira significativa no rendimento (Tabela 1). Maior rendimento foi registrado no grupo de cultivares crespas. Dentro dos grupos, as cultivares de alface Lucy Brown e Tainá dentro do grupo crespa e a Babá de Verão e Maravilha das Quatro Estações dentro do grupo lisa se destacaram das demais. No segundo plantio também não foi observada interação entre os fatores tratamentos e diferença significativa apenas entre grupos de cultivares (com o grupo crespa obtendo o maior rendimento), e entre cultivares dentro do grupo lisa no rendimento (com a cultivar Maravilha das Quatro Estações se sobressaindo das demais) (Tabela 1).

Observou-se que as cultivares de alface do grupo crespa Lucy Brown e Tainá se sobressaíram das demais, com relação ao desempenho produtivo, no primeiro plantio, tanto no cultivo sol- teiro como no cultivo consorciado. Estes resultados são discordantes em parte dos obtidos por Oliveira et al. (2002), onde não observaram comportamento diferencial entre cultivares de alface. Provavelmente, esta diferença não significativa entre as cultivares de alface se deva à época de plantio utilizada.

$O$ rendimento da alface no primeiro cultivo, no sistema consorciado, independentemente do grupo avaliado, foi cerca de $50 \%$ menor que o do cultivo solteiro. Estes resultados foram um pouco superiores aos obtidos por Andrade (2002) e inferiores aos obtidos por Oliveira et al. (2002), provavelmente devido às diferentes épocas de plantio da alface. Com relação ao segundo cultivo, o rendimento da alface do grupo crespa no sistema consorciado foi aproximadamente de $45 \%$ do cultivo solteiro, enquanto que a do grupo lisa foi cerca de $35 \%$ do sistema solteiro. Estas menores percentagens no segundo plantio se devem, provavelmente, em parte, à maior competição intra e inter-especifíca entre as culturas no consórcio.

No rendimento total, comercial e classificação de raízes da cenoura não se observou diferença significativa entre os níveis dos tratamentos testados (Tabela 2), o que significa dizer que as pressões de competição exercidas pelas cultivares de cenoura e pelas cultivares de alface sobre as variáveis da cenoura não foram suficientemente fortes a ponto de diferenciá-las. Estes resultados concordam em parte com os obtidos por Porto (1999) e Oliveira (2003), trabalhando com alguns dos tratamentos.

O rendimento total variou de 27,82 a $32,36 \mathrm{t} /$ ha e o comercial de 22,44 a 25,53 t/ha. A relação sistema consorciado/solteiro variou de $75 \%$ e $76 \%$ (em termos de rendimento total e comercial) a $90 \%$ e $89 \%$, que em média correspondeu a $81 \%$ da produtividade do cultivo solteiro. Estes resultados estão um pouco acima dos obtidos por Andrade (2002) e Oliveira (2003).

Maiores percentuais de raízes foram registrados nos tipos de raízes longas e médias (46 a 56\%), enquanto que os tipos curtos variaram de 23 a $36 \%$ e os fora de padrão (refugo) variaram de 14 a $22 \%$ (Tabela 2). Estes resultados discordam em parte dos obtidos por Andrade (2002), que trabalhando com outros tratamentos, obteve de 65 a $83 \%$ de raízes longas e 10 a $31 \%$ de raízes médias.

Verificou-se que os índices de uso eficiente da terra (UETs) dos diversos sistemas foram maiores que um (a unidade). Isto indica que nos sistemas consorciados ocorreu um melhor aproveitamento dos recursos ambientais, comparado com o do sistema solteiro. Esta 
Tabela 2. Rendimento total, comercial, relação consórcio/cultivo solteiro (para rendimento total e comercial) e classificação de raízes de cenoura em função de cultivares de cenoura, grupos e cultivares de alface dentro do grupo testadas. Mossoró-RN, ESAM, 2002.

\begin{tabular}{|c|c|c|c|c|c|c|}
\hline \multirow[b]{2}{*}{ Cultivares de cenoura } & \multicolumn{2}{|c|}{ Rendimento } & \multirow{2}{*}{$\begin{array}{l}\text { Consórcio/ } \\
\text { solteiro (\%) }\end{array}$} & \multicolumn{3}{|c|}{ Classificação (\%) } \\
\hline & Total (t/ha) & $\begin{array}{c}\text { Comercial } \\
(\mathrm{t} / \mathrm{ha})\end{array}$ & & $\begin{array}{l}\text { Longas e } \\
\text { médias }\end{array}$ & Curtas & Refugo \\
\hline & $*$ & & & & & \\
\hline Alvorada & 28,13 & 22,69 & $84 / 79$ & 48,93 & 32,17 & 18,89 \\
\hline Brasília & 31,30 & 25,28 & $79 / 84$ & 56,13 & 25,46 & 18,41 \\
\hline \multicolumn{7}{|l|}{ Grupos/cvs. de alface } \\
\hline CRESPA & 29,40 & 23,92 & $80 / 81$ & 51,43 & 30,75 & 17,82 \\
\hline Lucy Brown & 27,82 & 22,44 & $75 / 76$ & 52,76 & 28,13 & 19,11 \\
\hline Tainá & 29,28 & 23,39 & $80 / 80$ & 54,08 & 27,07 & 18,85 \\
\hline Laurel & 30,32 & 25,40 & $82 / 87$ & 52,47 & 32,13 & 15,40 \\
\hline Verônica & 30,16 & 24,48 & $81 / 83$ & 46,40 & 35,69 & 17,91 \\
\hline LISA & 30,03 & 24,05 & $83 / 82$ & 53,63 & 26,89 & 19,49 \\
\hline Babá de Verão & 30,48 & 23,63 & $83 / 81$ & 53,25 & 24,97 & 21,78 \\
\hline M. das Quatro Estações & 28,55 & 22,51 & $78 / 75$ & 50,65 & 27,92 & 21,43 \\
\hline Elisa & 28,75 & 24,52 & $82 / 84$ & 54,55 & 31,30 & 14,15 \\
\hline Carolina & 32,36 & 25,53 & $90 / 89$ & 56,09 & 23,32 & 20,59 \\
\hline$\overline{\text { C.V. (a) (\%) }}$ & 16,70 & 19,80 & & 23,43 & 49,12 & 36,09 \\
\hline C.V. (b) (\%) & 16,30 & 18,32 & & 15,97 & 28,94 & 33,36 \\
\hline C.V. (c) $(\%)$ & 11,34 & 17,75 & & 22,80 & 26,70 & 41,17 \\
\hline
\end{tabular}

* Não houve diferença significativa entre as médias das características avaliadas em todos os níveis dos fatores, ao nível de 5\% de probabilidade pelo teste de Duncan $(\mathrm{p}>0,05)$.

Tabela 3. Indicadores agroeconômicos de sistemas consorciados provenientes da combinação de duas cultivares de cenoura com dois grupos de quatro cultivares de alface em faixa. Mossoró-RN, ESAM, 2002.

\begin{tabular}{lrrrrrrr}
\hline Sistemas consorciados & UET & RB R\$/ha & RL R\$/ha & VM R\$/ha & VMC R\$/ha & TR & IL \% \\
\hline Alvorada + Lucy Brown & 2,16 & $39.452,29$ & $21.272,67$ & $20.731,47$ & $11.964,97$ & 2,17 & 53,92 \\
Brasília + Lucy Brown & 1,85 & $35.726,35$ & $17.565,23$ & $15.664,83$ & $9.621,62$ & 1,98 & 49,17 \\
Alvorada + Tainá & 1,93 & $36.641,91$ & $20.466,29$ & $17.593,68$ & $10.531,52$ & 2,27 & 55,85 \\
Brasília + Tainá & 1,83 & $35.170,04$ & $19.012,92$ & $15.083,83$ & $9.014,16$ & 2,18 & 54,06 \\
Alvorada + Laurel & 1,89 & $35.345,49$ & $17.545,87$ & $17.012,31$ & $9.080,64$ & 1,99 & 49,64 \\
Brasília + Laurel & 1,59 & $32.288,25$ & $14.507,13$ & $12.153,55$ & $6.351,91$ & 1,82 & 44,93 \\
Alvorada + Verônica & 1,67 & $31.075,34$ & $15.083,72$ & $12.705,92$ & $6.514,57$ & 1,94 & 48,54 \\
Brasília + Verônica & 1,94 & $36.344,21$ & $20.371,09$ & $17.128,64$ & $10.499,63$ & 2,27 & 56,05 \\
Alvorada + Babá de Verão & 1,77 & $33.771,08$ & $17.989,46$ & $14.719,67$ & $8.555,41$ & 2,14 & 53,27 \\
Brasília + Babá de Verão & 1,72 & $35.422,78$ & $19.659,66$ & $14.397,99$ & $8.481,63$ & 2,25 & 55,50 \\
Alvorada + M. Quatro Est. & 1,63 & $31.128,65$ & $14.459,03$ & $11.864,41$ & $5.841,56$ & 1,87 & 46,45 \\
Brasília + M. Quatro Est. & 2,15 & $38.958,28$ & $23.307,15$ & $19.828,59$ & $12.901,68$ & 2,49 & 59,83 \\
Alvorada + Elisa & 1,62 & $30.556,83$ & $14.597,21$ & $11.935,16$ & $5.992,55$ & 1,91 & 47,77 \\
Brasília + Elisa & 1,45 & $29.504,08$ & $13.562,96$ & $9.062,12$ & $5.013,64$ & 1,85 & 45,97 \\
Alvorada + Carolina & 1,61 & $29.923,15$ & $14.183,53$ & $11.255,49$ & $5.341,05$ & 1,90 & 47,40 \\
Brasília + Carolina & 1,90 & $36.048,10$ & $20.326,98$ & $16.511,24$ & $10.076,53$ & 2,29 & 56,39 \\
\hline
\end{tabular}

* UET- Índice de uso da terra; VM - vantagem monetária; IL - Índice de Lucratividade; RB - Renda bruta; VMc - vantagem monetária corrigida; RL - Renda líquida; TR - Taxa de retorno

vantagem no uso eficiente da terra $(45$ a $116 \%$ ) foi confirmada com indicadores econômicos nos seguintes sistemas consorciados: cenoura Alvorada + Lucy Brown e cenoura Brasília + Maravilha das Quatro Estações (Tabela 3).

As maiores rendas bruta e líquida foram observadas nos sistemas cenoura Alvorada + alface Lucy Brown (R\$ 39.452, 29 e $\mathrm{R} \$ 21.272,67)$, do grupo crespa e cenoura Brasília + alface Ma- ravilha das Quatro Estações ( $\mathrm{R}$ \$ $38.958,28$ e R $\$ 23.307,15)$ do grupo lisa (Tabela 3). Segundo Beltrão et al. (1984) a renda líquida expressa melhor o valor econômico dos sistemas do que a renda bruta, porque neles encontram-se deduzidos os custos de produção.

Os maiores indicadores de vantagem monetária (VM), de vantagem monetária corrigida (VMc) e também, de taxas de retorno (TR) e índices de lucratividade foram obtidos nos mesmos sistemas consorciados: cenoura Alvora$\mathrm{da}+$ alface Lucy Brown ( $\mathrm{R} \$ 20.731,47$; R\$ 11.964,97; 2,17 e 53,92\%) do grupo crespa e cenoura Brasília + alface Maravilha das Quatro Estações (R\$ $19.828,59 ; \mathrm{R} \$ 12.901,68 ; 2,49 \mathrm{e}$ $59,83 \%$ ) do grupo lisa, (Tabela 3). Estes resultados expressam a vantagem do uso eficiente da terra em termos monetários, indicando que a superioridade 
agronômica obtida neles traduziu-se em vantagens econômicas.

De modo geral, pode-se observar que, não houve interação significativa entre os fatores cultivares de cenoura e cultivares de alface em nenhum dos rendimentos avaliados nas culturas. Isto se deve a boa capacidade de combinação interespecífica entre os materiais testados. Não houve influência das cultivares de cenoura nos rendimentos das culturas. As cultivares de alface não afetaram nenhum dos rendimentos avaliados na cenoura. No bicultivo da alface consorciada com cenoura, recomenda-se o emprego das cultivares Lucy Brown e Tainá do grupo crespa ou da 'Babá de Verão' e 'Maravilha de Quatro Estações' do grupo lisa no primeiro plantio, pois estes foram os materiais que revelaram o máximo de seu potencial genético neste cultivo. No segundo plantio, apenas a cultivar do grupo lisa Maravilha das Quatro Estações se sobressaiu das demais no desempenho produtivo no cultivo consorciado. As cultivares de alface do grupo crespa foram, em geral, mais produtivas que as do grupo lisa, quando consorciadas com cenoura. A percentagem de raízes comerciais nos diversos sistemas consorciados foi de cerca de $80 \%$, sendo cerca de $52 \%$ constituído de raízes longas e médias e $28 \%$ de raízes curtas. Os consórcios cenoura 'Alvorada' e alface cv. 'Lucy Brown' e cenoura 'Brasília' e alface 'Maravilha das Quatro Estações’ foram os mais viáveis agroeconomicamente, com índices de uso eficiente da terra de 2,16 e 2,15, taxas de retorno de 2,05 e 2,33 , e índices de lucratividade de $53,92 \%$ e 59,83 , respectivamente.

\section{LITERATURA CITADA}

ANDRADE, F.V. Valor agroeconômico do consórcio alface e cenoura em dois sistemas de cultivo em faixas. 2002.81 p. (tese mestrado) ESAM, Mossoró-RN, 2002.

ANDRADE, F.V.; SANTOS JÚNIOR, J.J.; BEZERRA NETO, F.; NEGREIROS, M.Z. Desempenho de quatro cultivares de alface lisa em cultivo solteiro e consorciado com cenoura em dois sistemas de cultivos em faixas. Horticultura Brasileira, Brasília, v.19, n.2, Suplemento. CD-ROM. Trabalho apresentado no $41^{\circ}$ Congresso Brasileiro de Olericultura, 2001.

AZEVEDO JÚNIOR, M.S. Influência da configuração de plantio e cultivo no consórcio de beterraba (Beta vulgaris L.) e alface (Lactuca sativa L.). 1990. 43 p. (Monografia graduação) ESAM, Mossoró-RN, 1990.

BELTRÃO, N.E.M.; NOBREGA, L.B.; AZEVEDO, D.M.P.; VIEIRA, D.J. Comparação entre indicadores agroeconômicos de avaliação de agroecossistemas consorciados e solteiros envolvendo algodão "upland" e feijão "caupi". Campina Grande: CNPA, 1984. 21 p. (Boletim de pesquisa 15).

BEZERRA NETO, F.; ANDRADE, F.V.; NEGREIROS, M.Z.; SANTOS JÚNIOR, J.S. Desempenho agroeconômico do consórcio cenoura $\mathrm{x}$ alface lisa em dois sistemas de cultivo. Horticultura Brasileira, Brasília, v.21, n.4, p.635-641, 2003.

CAETANO, L.C.S.; FERREIRA, J.M.; ARAÚJO, M.L. Produtividade de cenoura e alface em sistemas de consorciação. Horticultura Brasileira, Brasília, v.17, n.2, p.143-146, 1999.

GARZIM, A.C. Estudo preliminar sobre o consórcio entre as culturas de cebola (Allium cepa L.) e de cenoura (Daucus carota L.). 1987. 45 p. (Monografia graduação) UNESP, Jaboticabal, 1987.
KHATOUNIAN, C.A. A reconstrução ecológica da agricultura. Botucatu: Agroecológica, 2001. 348 p.

NORUSIS, M.J. SPSS/PC Statistics. Illinois: SPSS Inc., 1990.320 p.

OLIVEIRA, A.M. Bicultivo de alfaces americanas consorciadas com cenoura em dois sistemas de cultivo em faixas. 2003. 34 f. (Tese mestrado). ESAM, Mossoró-RN, 2003.

OLIVEIRA, A.M.; BEZERRA NETO, F.; NEGREIROS, M.Z.; OLIVEIRA, E.Q.; GONDIM, A.R.O.; PORTO, D.R.Q.; FREITAS, K.K.C. Desempenho de cultivares de alface americana em consorciação com cenoura em dois sistemas de cultivo em faixas. Caatinga, Mossoró-RN, v.15, n.1/2, p.61-65, 2002.

PORTO, V.C.N. Cultivares de alface em sistema solteiro e consorciado com cenoura sob temperatura e luminosidade elevadas. 1999. $44 \mathrm{f}$. (Tese mestrado) ESAM, Mossoró-RN, 1999.

SALDANHA, T.R.F.C.; NEGREIROS, M.Z.; BEZERRA NETO, F. Cultivares de alface crespa em sistemas solteiro e consorciado com cenoura. In: SEMINÁRIO DE INICIAÇÃO CIENTÍFICA, 7., 2001, Mossoró. Resumos... Mossoró: ESAM, 2001. p.52-55.

SEMENTES SAKAMA. Características de cultivares de alface. São Paulo: Sementes Sakama, 2002. 2 p. (Mimeografado).

SOUZA, J.L.; RESENDE, P. Manual de horticultura orgânica. Viçosa: Aprenda Fácil, 2003. 564 p.

SOUZA, R.J.; MACHADO, A.Q.; GONÇALVES, L.D.; YURI, J.E.; MOTA J.H.; RESENDE, G.M. Cultura da cenoura. Lavras-MG: Editora UFLA, 2002. 68 p. (Textos Acadêmicos, 22).

SUDO, A.; GUERRA, J.G.M.; ALMEIDA, D.L.; RIBEIRO, R.L.D. Desempenhos de alface (Lactuca sativa L.) e cenoura (Daucus carota L.) consorciadas em sistema orgânico de produção. Horticultura Brasileira, Brasília-DF, v.15, Suplemento, 1997. (Resumo 308).

VIEIRA, J.V.; PESSOA, H.B.S.V.; MAKISHIMA, N. Cultivo da cenoura (Daucus carota L.). Brasília: CNPH, 1997. 19 p. (Instruções Técnicas, 13). 